\title{
Representaciones del Ingreso Ético Familiar: expresiones de la Gubernamentalidad chilena
}

\author{
Inti Fernando Fuica Rebolledo - Universitat Autònoma de Barcelona ${ }^{1}$
}

DOI: https://doi.org/10.5565/rev/periferia.615

\begin{abstract}
Resumen
El presente artículo sintetiza las principales reflexiones y hallazgos obtenidos a partir de la realización de una investigación ${ }^{2}$ que vincula las representaciones discursivas en torno al Ingreso Ético Familiar presentadas tanto por el Estado de Chile como por los principales medios de prensa escrita del mencionado país durante el año 2012. Mediante el Análisis Crítico del Discurso y la construcción de matrices analíticas se visibiliza la presencia de múltiples elementos propios de la gubernamentalidad neoliberal en la representación pública de este programa social. Finalmente, cerramos con una reflexión que nos permite abrir nuevos caminos de investigación en torno a los efectos prácticos de esta política pública.
\end{abstract}

Palabras clave: neoliberalismo, análisis crítico del discurso, gubernamentalidad, representaciones.

\section{Abstract. Representations of Family Ethical Income: Expressions from the Chilean Governmentality}

This article summarizes the main reflections and findings obtained from an investigation that links the discourse representations on Family Ethical Income presented by the State of Chile and the main written press media in the country during 2012. Through the Critical Analysis of the Discourse and the construction of analytical matrices, the presence of multiple elements of neoliberal governmentality in the public representation of this social program is made visible. Finally, we conclude with a reflection that allows us to open new research paths around the practical effects of this public policy.

Keywords: neoliberalism, critical discourse analysis, governmentality,

\footnotetext{
${ }^{1}$ Sociólogo (Universidad de Concepción, Chile, 2012), Máster en Antropología: Investigación avanzada e intervención social (Universitat Autònoma de Barcelona, 2017), doctorando en Antropología Social y Cultural (Universitat Autònoma de Barcelona). Enviar correspondencia a: Inti Fernando Fuica Rebolledo, inti.fuica.rebolledo@gmail.com

2 Presentada como Trabajo de Fin de Máster del Máster Oficial en Antropología: investigación avanzada e intervención social, de la Universitat Autònoma de Barcelona, bajo la dirección de la dra. Montserrat Clua i Fainé. Agradezco también al Estado de Chile y su programa de formación de capital humano avanzado Becas Chile de CONICYT, quienes financiaron estos estudios.
} 
Inti Fernando Fuica Rebolledo, Representaciones del Ingreso Ético Familiar: expresiones de la Gubernamentalidad chilena, perifèria 22(2), diciembre 2017

\section{revistes.uab.cat/periferia}

representations.

\section{Introducción}

La investigación que dio forma al Trabajo de Fin de Máster del cual se desprende este artículo fue un desafío para mí, toda vez que me sumergía en una temática nueva desde una disciplina novedosa. La antropología y sus enfoques teóricometodológicos, si bien cercanos a los que ya había utilizado desde la sociología, me entregaron nuevos matices para interpretar la realidad social. Este no fue un corte absoluto, sino que desde el comienzo la idea de estudiar antropología pasaba por la necesaria capacidad de complejizar mi capacidad analítica, sin que nunca fuera mi intención obviar mi formación de grado como sociólogo, que sigue impregnando gran parte de mi trabajo.

Mi intención inicial era estudiar al Estado chileno y su relación con la población chilena, así como mirar desde las ciencias sociales los efectos de la política del consenso que ha marcado la transición desde una dictadura hacia una democracia en mi país, manteniéndose muchos enclaves autoritarios que rigen la convivencia sociopolítica y la matriz productivo-económica, dificultando la expresión de las problemáticas sociales, así como la generación de cambios que transformaran las condiciones de vida de los chilenos y las chilenas (Fuica, 2016; Garretón, 2016a). Esta problemática tan general requería de forma urgente una acotación, la cual encontré mediante el estudio de las políticas públicas, entendidas como un vínculo directo entre el poder político y las poblaciones (Shore, 2010).

Al momento de determinar qué política pública, me decidí por el Ingreso Ético Familiar, ya que se trata de la principal política de protección social implementada por el Estado de Chile en la actualidad, focalizada en la población extremadamente pobre y cuya aprobación por el congreso fue unánime, como una expresión clara del consenso que ha caracterizado el devenir político en Chile desde la década de los 90 (Ahumada, Monreal, \& Tenorio, 2016; Martin, 2016; Vargas \& Socías, 2016).

\section{Estado y gubernamentalidad}

El estudio del Estado ha sido primordial para las ciencias sociales, tradición de la que 
Inti Fernando Fuica Rebolledo, Representaciones del Ingreso Ético Familiar: expresiones de la Gubernamentalidad chilena, perifèria 22(2), diciembre 2017

\section{revistes.uab.cat/periferia}

no pude hacerme cargo en su totalidad para la realización de esta investigación. Muy sintéticamente, uno de los aspectos más importantes que nos lega esta fecunda línea de investigación es la certeza de que el Estado es un fenómeno sociocultural, situado históricamente y fruto de diferentes luchas sociales, así como de condiciones políticas y económicas, y que a día de hoy su funcionamiento resulta crucial para el capitalismo neoliberal globalizado (Gramsci, 2006; Gupta \& Sharma, 2006; Shore, 2010; Wacquant, 2010).

El Estado no se confina a una maquinaria burocrático-administrativa que provee servicios y control social vía represión, sino que se extiende, influye y funde con la sociedad civil (Abelés, 1997; Foucault, 2006). Como un elemento crucial para poder analizar esta relación en la actualidad, emerge la representación, con sus diferentes mecanismos que buscan legitimar el actuar del Estado frente a las poblaciones (Abelés, 1997).

De una forma que permite analizar diferentes aspectos de la relación Estado poblaciones, Shore (2010) plantea que el accionar estatal se desenvuelve en dos campos distintos: el de las representaciones discursivas y mediáticas, por un lado; la performatividad práctica y cotidiana, por otro. Estos campos se encuentran en permanente diálogo y retroalimentación. En la presente investigación me centré, por cuestiones prácticas de tiempo y distancia -no tenía la posibilidad de realizar trabajo de campo en Chile encontrándome en Barcelona-, en las representaciones. Éstas se encuentran contenidas en el discurso público que el Estado entrega de sí mismo hacia la ciudadanía, por lo que podía acceder a éste desde mi ubicación actual.

El elemento que da cohesión y articula las representaciones y la performatividad es el de la gubernamentalidad, entendida -en su definición estrecha (Irusta, 2014)como los mecanismos implícitos a la voluntad de gobierno, que rigen el accionar del Estado sobre las poblaciones, articulando y siendo constitutivo tanto de los aspectos discursivos como prácticos propios del Estado (Foucault, 2006; Shore, 2010). Las políticas públicas, y más si cabe las políticas de protección social, son un vector de este accionar estatal en donde cristalizan y se ponen en directa relación con las poblaciones y el discurso público los elementos opacos de la gubernamentalidad (Shore, 2010). 
Inti Fernando Fuica Rebolledo, Representaciones del Ingreso Ético Familiar: expresiones de la Gubernamentalidad chilena, perifèria 22(2), diciembre 2017

\section{revistes.uab.cat/periferia}

\section{Neoliberalismo}

A modo de hipótesis de trabajo, consideré que la gubernamentalidad en Chile debiese poseer una marcada tendencia neoliberal. Esto es debido a que, desde el periodo de la dictadura militar (1973 - 1990), en Chile se implementan reformas macroeconómicas y políticas inspiradas en esta ideología, transformándose el país en una especie de laboratorio de pruebas que finalmente cristalizaron en las extendidas medidas internacionales conocidas como consenso de Washington (Ahumada et al., 2016; Fuica, 2016; Garretón, 2016b; Martin, 2016; Martínez \& Soto, 2012). El rol subsidiario del Estado, la focalización del gasto público y el rol prioritario del mercado y la competencia son algunos cambios cruciales en esta transformación. Si bien estas medidas demostraron, a largo plazo, influir positivamente en los niveles de crecimiento económico, la pobreza y la desigualdad se mantienen como importantes problemáticas que deben ser paliadas con medidas correctivas (Galasso, 2011; International Poverty Centre, 2006; OECD, 2015; Segovia \& Gamboa, 2015).

Simultáneamente, se adelgazan las políticas de protección social, se abandona el afán universalista de los derechos, y se concibe a la persona como un consumidor antes que como sujeto de derechos (Wacquant, 2010). Esta situación acarrea una doble transformación por parte del Estado: mientras disminuye su capacidad de control en el devenir económico de las naciones y en las capas más altas de la sociedad, aumenta su función punitivo-coercitiva, afectando principalmente a las capas más pobres (Wacquant, 2010). Se produce entonces lo que Wacquant denomina el "tropo cultural de la responsabilidad individual" (2010, p. 431), fomentándose desde el Estado la emergencia de algunas conductas deseables en las poblaciones para que estas puedan ser beneficiarias de la protección social.

\section{Políticas de protección social}

Desde el periodo dictatorial, en donde la ideología neoliberal penetró con fuerza en el Estado chileno, las políticas de protección social en Chile han pasado por varias etapas. De forma extremadamente sintética, podemos caracterizarlas así: el rol del Estado se reduce dramáticamente durante la dictadura militar (1973 - 1990); en la década de los 90 y bajo gobiernos demócrata-cristianos se administra esta herencia 
Inti Fernando Fuica Rebolledo, Representaciones del Ingreso Ético Familiar: expresiones de la Gubernamentalidad chilena, perifèria 22(2), diciembre 2017

\section{revistes.uab.cat/periferia}

y se priorizan otras áreas; en la década de los 2000 los gobiernos a cargo del partido socialista chileno buscan incrementar la participación estatal para aumentar la equidad en la sociedad chilena (Martin, 2016). De todas maneras, la autora señala que el modelo neoliberal de las políticas de protección social (privados proveyendo servicios, mercado laboral desregulado, focalización de las políticas sociales y un bajo gasto social) se mantuvo fundamentalmente inalterado (Martin, 2016).

Una vez que en el año 2010 asume la presidencia Sebastián Piñera e instaura un gobierno de derecha, este afán se abandona y se reformula el sistema Chile Solidario hacia el denominado Ingreso Ético Familiar ${ }^{3}$, con una orientación mucho más fuerte hacia el empleo, un refuerzo en las condicionalidades y un incremento en el número y el monto de las transferencias monetarias asociadas (Ahumada et al., 2016; Martin, 2016; Vargas \& Socías, 2016). El IEF se constituye como una Política de Transferencia Monetaria Condicionada ${ }^{4}$, que se han posicionado como las principales políticas públicas de lucha contra la pobreza en Latinoamérica, y que constan de la transferencia directa de dinero desde el Estado hacia las personas que cumplen los criterios para ser considerados como beneficiarios (Correa, 2009; International Poverty Centre, 2006).

En términos muy generales, el IEF es un programa de seguridad social a cargo del Ministerio de Desarrollo Social ${ }^{5}$, y posee dos componentes principales: en primer lugar, existen diferentes programas de apoyo a los integrantes de la familia, ya sea de apoyo social y de apoyo laboral, así como de información respecto de otros beneficios del Estado a los que pueden acceder (Fuica, 2017; Ministerio de Desarrollo Social, 2017). En segunda instancia, están las diferentes transferencias monetarias, conocidas en Chile como bonos, de las cuales algunas son por encontrarse en

\footnotetext{
${ }^{3}$ Si bien el nombre oficial es Sistema Seguridades y Oportunidades, el proyecto fue presentado al Congreso bajo el nombre Ingreso Ético Familiar, refiriéndose al programa con este nombre hasta la actualidad tanto las autoridades como la prensa chilena. En este artículo también utilizaré las siglas IEF para referirme al citado programa.

${ }^{4}$ En adelante, PTMC.

${ }^{5}$ En adelante, MDS.
} 
Inti Fernando Fuica Rebolledo, Representaciones del Ingreso Ético Familiar: expresiones de la Gubernamentalidad chilena, perifèria 22(2), diciembre 2017

\section{revistes.uab.cat/periferia}

situación de extrema pobreza (sin condiciones), y otras dependen del cumplimiento de algunas tareas y compromisos adquiridos por la familia (condicionadas) ${ }^{6}$ (Fuica, 2017; Ministerio de Desarrollo Social, 2017).

\section{Procedimiento metodológico}

Con el afán de analizar las representaciones construidas en torno al IEF, se tornó necesario identificar discursos en donde estuviese presente este programa, en donde existiera una pluralidad de miradas en torno a éste y que además tuviesen impacto en la sociedad chilena. Así, seleccioné como fuentes de los datos a recoger las comunicaciones oficiales del Estado chileno respeto del IEF, tanto desde las comunicaciones oficiales del MDS como de la página web oficial del programa. También incluí los dos principales medios de comunicación escrita en Chile, los periódicos El Mercurio y La Tercera. Como las líneas editoriales de estos medios presentaban más similitudes que diferencias, además de una clara cercanía con el gobierno de Sebastián Piñera, se incluyó también la plataforma de periodismo de investigación CIPER Chile.

La búsqueda se realizó en los archivos correspondientes al año 2012, debido a que en estas fechas fue cuando el proyecto se envió a trámite legislativo, siendo discutido y aprobado de forma unánime por el Congreso nacional. Todos los documentos analizados corresponden a este año, con la excepción de la página web oficial, cuya fecha de publicación no pudo ser determinada, y que está sujeta a permanentes cambios y actualizaciones.

En el caso de los diarios, se revisaron las versiones digitalizadas de cada edición, desde el 1 de enero de 2012 hasta el 31 de diciembre del mismo año, y se seleccionaron todas las noticias, editoriales y columnas de opinión en donde aparecía mencionado el IEF. En CIPER Chile, la búsqueda se realizó mediante palabras clave

\footnotetext{
6 Para una revisión más exhaustiva de estos componentes, se pueden revisar la página web www.ingresoetico.gob.cl (Ministerio de Desarrollo Social, 2017), o bien el Trabajo de Fin de Máster del autor (Fuica, 2017).
} 
Inti Fernando Fuica Rebolledo, Representaciones del Ingreso Ético Familiar: expresiones de la Gubernamentalidad chilena, perifèria 22(2), diciembre 2017

\section{revistes.uab.cat/periferia}

en el año 2012. Para las comunicaciones oficiales del MDS, se revisó día por día las publicaciones en el apartado "noticias". La página web oficial del IEF fue considerada en su totalidad. La muestra final quedó constituida por 113 documentos, repartidos de la siguiente forma:

Tabla 1: Unidades de Observación

\begin{tabular}{|c|c|c|}
\hline & Fuentes & Documentos Analizados \\
\hline \multirow[t]{2}{*}{$\begin{array}{l}\text { Plataformas } \\
\text { comunicacionales del } \\
\text { Estado }\end{array}$} & $\begin{array}{l}\text { Comunicaciones del } \\
\text { Ministerio de Desarrollo } \\
\text { Social (MDS) }\end{array}$ & 19 \\
\hline & $\begin{array}{l}\text { Página web del IEF } \\
\text { (PWIEF) }\end{array}$ & 4 \\
\hline \multirow{3}{*}{$\begin{array}{l}\text { Plataformas de medios de } \\
\text { comunicación masiva }\end{array}$} & Diario La Tercera (LT) & 20 \\
\hline & Diario El Mercurio (EM) & 66 \\
\hline & CIPER Chile (CIPER) & 4 \\
\hline
\end{tabular}

Fuente: elaboración propia.

Para analizar los documentos encontrados, me basé en los lineamientos propuestos por el enfoque conocido como Análisis Crítico del Discurso7 ${ }^{7}$. El método de análisis es parte de la importante tradición hermenéutica de las ciencias sociales, y se propone de forma circular: desde el discurso/texto se interpreta en relación a los antecedentes teóricos; se operacionaliza y se retorna al texto (Meyer, 2003; Ruiz Olabuénaga, 2007; Van Dijk, 2003; Wodak, 2003). El discurso se considera como formativo de sociedad, y como un vehículo del ejercicio del poder (Jäger, 2003; Wodak, 2003), por lo que la principal meta del análisis es develar los mecanismos de acción de este poder y los elementos que se entregan de forma opaca a la sociedad, situación crucial para la realización de esta investigación (Jäger, 2003; Wodak, 2003).

En términos más prácticos, se establecieron de forma teórica elementos propios de la ideología neoliberal (rol subsidiario del Estado; crecimiento económico; individualismo; competencia; mérito; focalización, entre otros) que se fueron identificando en los diferentes discursos recabados. Para realizar un análisis

\footnotetext{
7 En adelante, ACD.
} 
Inti Fernando Fuica Rebolledo, Representaciones del Ingreso Ético Familiar: expresiones de la Gubernamentalidad chilena, perifèria 22(2), diciembre 2017

\section{revistes.uab.cat/periferia}

coherente y ordenado, desarrollé tres matrices analíticas que responden a tres niveles de análisis: la primera, contextual, de descripción global de los discursos y su ubicación longitudinal durante el año 2012; la segunda matriz es de contenido, en donde se profundizaba en el análisis particular de cada documento y fuente de información recabada; y la tercera matriz, llamada ideológica, en donde se vinculaban transversalmente los elementos de los discursos analizados con los principales componentes de la ideología neoliberal.

\section{Algunos hallazgos de investigación}

Si bien no puedo exponer aquí de forma pormenorizada los resultados de cada una de las matrices utilizadas para el análisis de los 113 documentos, sí aspiro a generar una síntesis de los principales hallazgos, que puedan además entregarnos elementos fructíferos para su discusión ulterior ${ }^{8}$. Los hallazgos más relevantes se concentran en la matriz ideológica, y es en estos resultados en los cuales me centraré en el presente apartado, con algunos elementos particularmente interesantes aportados por las otras matrices analíticas.

En este sentido, es importante mencionar que sólo en 42 de estos 113 documentos la relevancia del IEF fue considerada como central: la noticia giraba en torno al programa y trataba mayoritariamente sobre éste. Si bien a priori esto puede considerarse como una dificultad o debilidad, resultó en extremo útil para poder comprender también con qué otros temas se vincula el IEF, y fue fundamental también para poder comprender de manera más holista el discurso del Estado.

Uno de los aspectos generales más interesantes es la profundidad y extensión del seguimiento realizado por el diario El Mercurio al IEF. Más de la mitad de los documentos analizados fueron publicados por este medio de comunicación, dentro de los cuales encontramos 13 editoriales, 7 entrevistas -cuatro al ministro de Desarrollo Social durante 2012, y tres al presidente de la República de Chile en el

\footnotetext{
8 Para una exposición detallada de los resultados por cada una de las matrices, ver el Trabajo de Fin de Máster del autor (Fuica, 2017).
} 
Inti Fernando Fuica Rebolledo, Representaciones del Ingreso Ético Familiar: expresiones de la Gubernamentalidad chilena, perifèria 22(2), diciembre 2017

\section{revistes.uab.cat/periferia}

mencionado año-, y 7 columnas de opinión. En la totalidad de estos 27 documentos de opinión, se defiende a ultranza al IEF como una política pública de protección social cuyos efectos positivos son innegables: tanto para las personas que recibirán los beneficios entregados por el Estado, como para el funcionamiento macroeconómico en general:

"se complementa el salario mínimo (o valores cercanos a él) con subsidios, algunos de los cuales se entregan a las familias por el solo hecho de estar en situación de pobreza, y otros según mérito, que puede estar relacionado con el esfuerzo que las personas desplieguen en el cuidado y estudio de sus hijos, aunque también podría estar asociado al hecho de tener trabajo con una remuneración cercana al mínimo. Así se pueden elevar los ingresos de las familias en peor condición, sin distorsionar negativamente el mercado del trabajo y evitando que crezca el desempleo" (EM. 2012-05-11 (1)).

Esta visión positiva del IEF la encontramos también en las comunicaciones oficiales del MDS, y en menor medida en las publicaciones del diario La Tercera. Las visiones más críticas las entrega CIPER Chile, cuestionando el modelo de asistencia social vía bonos que no modifica las condiciones estructurales que producen pobreza, así como destacan que la cobertura del IEF es insuficiente para la población que realmente se encuentra en situación de pobreza:

"Subsidios monetarios basados en ingresos reales, que sean redistributivos y administrados por el sistema tributario, que exijan formalización de actividades y generación de ingreso autónomos. Que abarquen a las "familias de menores ingresos", que son cerca del 25\% de la población" (CIPER. 2012-03-05).

Dentro de la totalidad de los documentos analizados, existe también un gran número dedicado a la explicación de los diferentes componentes del IEF y a la población objetivo. Los periódicos El Mercurio y La Tercera, así como las comunicaciones oficiales del MDS, repiten una y otra vez los componentes de este programa, información que es sintetizada en la página web del IEF:

"Es un beneficio que otorga el Estado como apoyo directo a las personas y familias de menores ingresos, para favorecer a las personas más vulnerables 
Inti Fernando Fuica Rebolledo, Representaciones del Ingreso Ético Familiar: expresiones de la Gubernamentalidad chilena, perifèria 22(2), diciembre 2017

\section{revistes.uab.cat/periferia}

con el objetivo de superar la pobreza extrema. Funciona a través de programas que trabajan de manera personalizada en el ámbito social y laboral, promoviendo el desarrollo de la familia, su autonomía y potenciando además sus capacidades que le faciliten incorporarse al mundo del trabajo. Estos programas están asociados a la entrega de bonos de acuerdo al reconocimiento de logros y el cumplimiento de deberes, en áreas de salud, educación y trabajo" (PWIEF. Qué es el IEF).

Si nos movemos ya a los elementos más ideológicos -el análisis de la gubernamentalidad- vehiculizados en los discursos públicos construidos en torno al IEF, vemos como claramente en esta política pública se expresa el neoliberalismo como voluntad de gobierno en Chile. Algunos de estos elementos se encuentran presentes de forma explícita en el discurso, mientras otros aparecen velados, y sólo mediante la interpretación y diálogo con los antecedentes teóricos es que se pueden señalar con certeza.

El rol subsidiario del Estado es uno de los principales elementos a considerar, expresado de forma muy clara en la característica principal de toda PTMC: la transferencia directa de dinero desde el Estado hacia el beneficiario. Esto implica que no existe mayor infraestructura estatal, así como se entrega la libertad de decidir en qué invertir su dinero al destinatario de la transferencia. Esta característica se constata y es destacada como representativa del IEF en su totalidad:

"Según datos de La Moneda, esta iniciativa contempla un bono base a las familias de extrema pobreza, otro asociado a "logros y deberes" -como asistencia de niños a clases y visitas al día al consultorio-, más un subsidio al empleo a la mujer. Con esto, cerca de 170 mil familias podrían llegar a recibir hasta \$ 90 mil mensuales" (LT. 2012-05-15).

Por su parte, el ministro de Hacienda en ejercicio durante el año 2012, Felipe Larraín, ubica al crecimiento económico como crucial en la lucha contra la pobreza, más allá de los aportes que puede realizar el Estado:

"Para lograrlo [disminución pobreza], el crecimiento económico y el empleo le ganaron la batalla al terremoto y al alza de precio de los alimentos. Entre 2010 
Inti Fernando Fuica Rebolledo, Representaciones del Ingreso Ético Familiar: expresiones de la Gubernamentalidad chilena, perifèria 22(2), diciembre 2017

\section{revistes.uab.cat/periferia}

y 2011 nuestra economía creció en promedio sobre 6\%, creó más de 700 mil empleos, y los salarios aumentaron en torno a 6\% nominal anual" (EM. 201207-29 (1)).

De esta manera, la máxima autoridad en términos fiscales del país subyuga directamente la superación de la pobreza al mero crecimiento económico y la generación de empleo, sin ingresar en aspectos como la desigualdad o la calidad de los trabajos generados. En estos discursos, que son ejemplos paradigmáticos de ideas repetidas por las autoridades de gobierno de la época, subyace una de las bases ideológicas cruciales para la ideología neoliberal: el individualismo. Si bien no se menciona de forma explícita, sí está presente la idea de que la pobreza es una problemática individual, y las personas deben salir de esta situación también de forma particular:

"El Ingreso Ético Familiar busca que las personas superen la pobreza por sí mismas, es decir, con su propio esfuerzo. Para eso se establece una verdadera alianza estratégica entre el Estado y las familias, con compromisos mutuos" (MDS. 2012-05-01).

Cuando el Estado chileno plantea la idea de la superación individual de la pobreza, se está desligando absolutamente de su capacidad de incidencia en las condicionantes estructurales de la pobreza en Chile. Es importante volver a dar cuenta de cómo desde el aparato estatal -tampoco en los medios de comunicación, con la excepción de CIPER Chile- no se hace mención a la falta de derechos sociales, de acceso a educación y salud públicas de calidad, de la carencia de vivienda y de la falta de programas de empleo para jóvenes, sino que, desde el Estado, se otorga la responsabilidad a cada pobre de escapar de su propia situación, contando sólo con apoyos puntuales en situaciones extremas. Esta idea, expresada en el párrafo anterior por el MDS como organización social, es también defendida e impulsada por Joaquín Lavín, ministro de Desarrollo Social durante 2012:

"Esto pasa por el convencimiento de que la persona sale de la pobreza con su propio esfuerzo. Es la persona que, con sus ganas, esfuerzo y voluntad, sale de la pobreza. El concepto que hay aquí es que la gente tiene que salir de la pobreza por sí sola, con un empujón que le da el Estado" (EM. 2012-01-22 (2)). 
Inti Fernando Fuica Rebolledo, Representaciones del Ingreso Ético Familiar: expresiones de la Gubernamentalidad chilena, perifèria 22(2), diciembre 2017

\section{revistes.uab.cat/periferia}

El empujón del Estado es sólo eso, una pequeña ayuda, el resultado final depende del esfuerzo de cada uno. Quizás por tratarse sólo de un impulso es que ni las autoridades ni los medios de comunicación ponen mucho énfasis en la duración acotada del IEF -normalmente 24 meses, máximo 36-. Tampoco se hace ninguna referencia a qué es lo que sucede una vez que los beneficiarios egresan del programa. EI IEF además posee otro elemento ampliamente celebrado en la gran mayoría de los documentos analizados: la focalización de los recursos del Estado destinados a la superación de la pobreza extrema. Así lo destaca el ministro de Desarrollo Social, Joaquín Lavín, en una entrevista concedida a El Mercurio:

"En la medida en que la pobreza extrema vaya cayendo, las políticas obviamente deben ser más focalizadas, y esas cinco regiones, probablemente, sean las primeras en cumplir esta meta presidencial. Por eso, nosotros -como Ministerio de Desarrollo Social- tendremos que trabajar directamente con los intendentes y gobiernos regionales para diseñar políticas más específicas" (EM. 2012-07-22).

Esta manera de entender las políticas de protección social, destinadas en la práctica a rebajar los índices estadísticos de pobreza a través de un aumento en el ingreso familiar mensual, vuelve a difuminar otras carencias que mantienen a un amplio número de personas en situación de pobreza, ya que no se menciona en ningún punto la calidad de la vivienda, el acceso a servicios básicos o las posibilidades de movilidad social. En las páginas de La Tercera, el propio presidente Piñera destaca al IEF, centrado en las 170.000 familias más pobres, como la mejor manera para reducir los índices de pobreza:

"A pesar de que su visita al albergue no estuvo exenta de problemas, luego de que algunos albergados lo criticaran, el Presidente aseguró que el gobierno está comprometido en derrocar la pobreza extrema, afirmando que "es el imperativo moral más profundo del gobierno". Para esto, el Mandatario reiteró las medidas que están llevando a cabo, como la aprobación del Ingreso Ético Familiar, el cual beneficiará a 170 mil familias, y la asociación con el Hogar de Cristo para devolver a personas en situación de calle a hogares comunitarios" (LT. 201205-08). 
Inti Fernando Fuica Rebolledo, Representaciones del Ingreso Ético Familiar: expresiones de la Gubernamentalidad chilena, perifèria 22(2), diciembre 2017

\section{revistes.uab.cat/periferia}

Sumado a lo anterior, se constata de manera explícita en los discursos analizados que el apoyo estatal para superar la pobreza extrema no es un derecho social, sino que implica necesariamente que las personas beneficiadas también se esfuercen y merezcan ser apoyadas por el Estado. El propio ministro de Desarrollo Social, Joaquín Lavín, envía este mensaje a través de las páginas del El Mercurio, replicando una de las ideas fuerza de la administración Piñera:

"Sociedad de derechos, pero también de deberes. La nueva política social no se construye desde el asistencialismo, sino desde el acento en la responsabilidad individual y el premio al esfuerzo. Premio al cumplimiento de deberes en educación y salud: incluido en el bono por deberes que establece el Ingreso Ético Familiar" (EM. 2012-03-11 (2)).

Este necesario mérito individual para la recepción de un apoyo estatal más importante involucra a las personas más pobres de la sociedad chilena en una competencia particular, un tanto perversa, en donde sólo a los mejores dentro de los más pobres se entregan recursos adicionales, a modo de premio:

"Se premiará a las familias cuyos hijos destaquen en los estudios y estén en el $30 \%$ de los mejores alumnos de su curso (bono de 50 mil pesos); y también se premiará el trabajo de la mujer (bono de hasta 25 mil pesos)" (MDS. 2012-0416).

Si bien ni los medios de comunicación masiva ni las autoridades mencionan explícitamente esta competencia, sólo un tercio de los estudiantes que pertenecen a las 170.000 familias más pobres de Chile pueden acceder a este bono suplementario. La focalización dentro de la focalización, la competencia dentro del mérito, y el individualismo como telón de fondo para una problemática estructural como la pobreza marcan los discursos aquí analizados.

Para cerrar este apartado, quisiera incluir un importante componente ideológico que, si bien no podemos vincularlo con el neoliberalismo de acuerdo a lo revisado en la teoría, sí que impregna y determina el discurso sobre el IEF. Este elemento está presente de forma explícita hasta en el nombre del programa, y es el sesgo familiar que atraviesa esta política pública. En la clásica combinación de liberalismo 
Inti Fernando Fuica Rebolledo, Representaciones del Ingreso Ético Familiar: expresiones de la Gubernamentalidad chilena, perifèria 22(2), diciembre 2017

\section{revistes.uab.cat/periferia}

económico y conservadurismo valórico de la derecha, aquí son la familia, y más específicamente la mujer, los ejes de los esfuerzos para la reducción de la pobreza, como explica el ministro Joaquín Lavín en una entrevista concedida al diario El Mercurio:

"Jugados por la familia. Las políticas pro familia surgen del convencimiento de que las capacidades para salir adelante en la vida, y alcanzar la realización personal y la felicidad, se juegan ahí [...] La mujer en el centro: por eso el Ingreso Ético Familiar se paga directamente a la mujer y se premia específicamente con un subsidio al empleo" (EM. 2012-03-11 (2)).

Este sesgo ideológico de Género es revisado en profundidad por Ahumada, Monreal y Tenorio (2016), quienes develan cómo los estereotipos más tradicionales respecto de la mujer y su rol en la familia continúan presentes en, y son además promovidos por, el IEF.

\section{Discusión y apertura}

Aunque el Ingreso Ético Familiar es una política pública que, como vimos más arriba, posee unos alcances altamente focalizados, funciona para el presente análisis como una excelente puerta de entrada hacia la voluntad de gobierno de carácter neoliberal que sustenta la gubernamentalidad del Estado chileno (Foucault, 1990, 2006; Shore, 2010). Al centrarme sólo en esta política pública, pude contar con un importante eje vertebrador para la búsqueda de datos, el análisis de la información y el ordenamiento de un texto que pudiese responder de forma adecuada a los objetivos de caracterizar la gubernamentalidad chilena. Así, en los discursos generados en torno al IEF se condensan gran parte de los lineamientos ideológicos más representativos del neoliberalismo, y permiten afirmar con certeza que esta impronta domina el accionar del Estado de Chile, en consonancia con los antecedentes recabados (Fuica, 2016; Garretón, 2016a, 2016b). Si bien el ejercicio de constatación de la impronta neoliberal puede parecer una crónica de una muerte anunciada, no es un ejercicio inútil, toda vez que esta política pública había sido evaluada siempre desde aspectos cuantitativos (Martin, 2016; Vargas \& Socías, 2016), o bien en relación con el enfoque de derechos (Vargas \& Socías, 2016) o el enfoque de género 
Inti Fernando Fuica Rebolledo, Representaciones del Ingreso Ético Familiar: expresiones de la Gubernamentalidad chilena, perifèria 22(2), diciembre 2017

\section{revistes.uab.cat/periferia}

(Ahumada et al., 2016).

Al momento de legitimar su accionar frente a la pobreza extrema mediante el IEF, prácticamente no existe batalla ideológica alguna (Abelés, 1997), siendo la única voz disidente y crítica la de CIPER Chile, pero con una presencia en la agenda pública mucho menor al de los diarios La Tercera y El Mercurio. Asimismo, los canales de comunicación del Estado (noticias del MDS y la página web del IEF) cumplen con el rol esperado de propaganda y relevamiento de los aspectos positivos. La maquinaria de propaganda aquí analizada tiene como finalidad copar el sentido común y sostener la relación hegemónica aquí vehiculizada, asegurando la recepción positiva de esta política pública y acallando los potenciales cuestionamientos con anterioridad a su implementación (Gramsci, 2006; Shore, 2010).

Quizás uno de los elementos más importantes de los analizados es aquel relativo a la individualización de la situación de pobreza. En línea con los efectos culturales del neoliberalismo planteados por Wacquant (2010), la propuesta explícita por parte de la administración Piñera pasa por responsabilizar a los individuos de superar esta condición, siendo el Estado un apoyo puntual y no el garante de derechos sociales (Vargas \& Socías, 2016). Es importante recalcar aquí que, para poder establecer una afirmación de esta índole, el ejercicio hermenéutico y crítico resulta crucial, ya que es sólo a través de la interpretación que puedo posicionar al individualismo como uno de los ejes principales del IEF, en un diálogo circular entre lo que los textos dicen y lo que la teoría nos aporta para su comprensión. Si hubiésemos analizado de forma cuantitativa los mismos 113 textos, la palabra individualismo -o individuo- no hubiese emergido como una de las más importantes.

Si bien las representaciones aquí analizadas pueden dar la impresión de que no existe ninguna resistencia a esta situación, esto pasa también porque ninguna de las fuentes releva en demasía los discursos de los propios beneficiarios del IEF: cuando su voz aparece, es inevitablemente en términos de agradecer la ayuda, de aceptar el beneficio y de celebrar el accionar gubernamental. La verticalidad de la política pública es tal, que al IEF ni siquiera se postula, sino que es el propio Estado con sus propios mecanismos el ente que define quién queda incluido dentro del IEF y quién queda fuera (Ministerio de Desarrollo Social, 2017). 
Inti Fernando Fuica Rebolledo, Representaciones del Ingreso Ético Familiar: expresiones de la Gubernamentalidad chilena, perifèria 22(2), diciembre 2017

\section{revistes.uab.cat/periferia}

Como queda claro, la investigación aquí presentada acusa algunas limitaciones importantes: establecer que la gubernamentalidad chilena es de carácter neoliberal no es nuevo, a pesar de que sí sea novedoso realizarlo mediante el análisis del IEF; la presencia de voces críticas con el IEF es escasa, aunque esto pueda achacársele al cerco ideológico-financiero existente en los medios de comunicación chilenos (Monckeberg, 2011); se extraña sobremanera la voz de los actores implicados de forma directa en el funcionamiento del IEF, desde los técnicos que lo implementan hasta los receptores de esta política pública. Aun así, me parece que sí se establece un sólido punto de partida para poder profundizar en esta temática, y buscar así subsanar algunas de estas deficiencias mediante la realización de una tesis doctoral que incluya estos aspectos.

Como se señaló más arriba, el IEF es una Política de Transferencia Monetaria Condicionada, forma de programa social para disminuir la pobreza que se ha extendido rápidamente casi por la totalidad de América Latina, toda vez que no requiere de inversión en infraestructura y permite focalizar el gasto y mejorar rápidamente las estadísticas de ingreso (Correa, 2009; International Poverty Centre, 2006). Una de las principales carencias de las PTMC es la falta de evaluaciones cualitativas, y en especial investigaciones etnográficas, de su desempeño, que involucren a los propios beneficiarios de la política pública en el ejercicio de determinar cuán exitosa ha resultado ésta (Correa, 2009). De ahí que se desprende como una importante necesidad -y un deber- la incorporación de las personas consideradas como extremadamente pobres en ulteriores etapas de esta investigación.

El Ingreso Ético Familiar es un engranaje más dentro de los diferentes dispositivos de control social que despliega el Estado chileno (Foucault, 2006; Irusta, 2014; Shore, 2010), cuya importancia radica en que se focaliza en los sujetos más pobres de la sociedad chilena. Indagar en los efectos culturales que pueda acarrear el pertenecer a este programa (Wacquant, 2010), en los mecanismos institucionales desplegados para su ejecución práctica y cotidiana (Escobar, 2007; Shore, 2010) y dar voz a la experiencia de sus principales participantes (Correa, 2009) son algunas de las tareas a realizar para poder dar correcta cuenta del Estado chileno y sus 
Inti Fernando Fuica Rebolledo, Representaciones del Ingreso Ético Familiar: expresiones de la Gubernamentalidad chilena, perifèria 22(2), diciembre 2017

\section{revistes.uab.cat/periferia}

prácticas de gubernamentalidad.

\section{Bibliografía}

Abelés, M. (1997). La antropología política: nuevos objetivos, nuevos objetos. International Social Science Journal, 49(153), 319-332. https://doi.org/10.1111/j.1468-2451.1997.tb00026.x

Ahumada, K., Monreal, T., \& Tenorio, L. (2016). Representaciones sociales de género : La (s) mujer (es)/madres como un instrumento para el Desarrollo en el Programa gubernamental chileno Ingreso Ético Familiar. Revista CS, (18), 159181. https://doi.org/10.18046/recs.i18.1943

Correa, N. (2009). Programas de Transferencias Condicionadas: aportes para el debate público. Economía y Sociedad, 71, 74-80.

Escobar, A. (2007). La invención del Tercer Mundo. Construcción y deconstrucción del desarrollo. (D. Reyes, Ed.). Caracas: Fundación Editorial el perro y la rana.

Foucault, M. (1990). Tecnologías del yo. Y otros textos afines. Barcelona: Paidós Ibérica.

Foucault, M. (2006). Governmentality. En A. Gupta \& A. Sharma (Eds.), Anthropology of the State. A reader (pp. 131-143). Oxford: Blackwell Publishing.

Fuica, I. F. (2016). Modelos de desarrollo, identidad masculina y familia: dos generaciones de trabajadores de Huachipato. Revista Punto Género, (6), 43-59. https://doi.org/10.5354/0719-0417.2016.42915

Fuica, I. F. (2017). Gubernamentalidad y Estado Chileno: El Ingreso Ético Familiar y su representación como política pública (trabajo de fin de máster). Universidad Autónoma de Barcelona.

Galasso, E. (2011). Alleviating extreme poverty in Chile: the short term effects of Chile Solidario. Estudios de economía, 38(1), 101-127. https://doi.org/10.4067/S0718-52862011000100005

Garretón, M. A. (2016a). Crisis de representación, movilizaciones sociales y 
Inti Fernando Fuica Rebolledo, Representaciones del Ingreso Ético Familiar: expresiones de la Gubernamentalidad chilena, perifèria 22(2), diciembre 2017

revistes.uab.cat/periferia

elecciones presidenciales 2013 en Chile. En F. Mayorga (Ed.), Elecciones y legitimidad democrática en América Latina (pp. 15-37). Santiago de Chile: CLACSO.

Garretón, M. A. (2016b). Los Desafíos del Estado Contemporáneo. En L. Rebolledo (Ed.), Pensar Chile desde las Ciencias Sociales y las Humanidades. Territorio, ausencia, crisis y emergencias (pp. 19-30). Santiago de Chile: Editorial Universitaria.

Gramsci, A. (2006). State and Civil Society. En A. Gupta \& A. Sharma (Eds.), Anthropology of the State. A reader (pp. 71-85). Oxford: Blackwell Publishing.

Gupta, A., \& Sharma, A. (2006). Introduction: Rethinking Theories of the State in an Age of Globalization. En A. Gupta \& A. Sharma (Eds.), Anthropology of the State. $A$ reader ( $1^{\text {a }}$ ed., pp. 1-41). Oxford: Blackwell Publishing.

International Poverty Centre. (2006). Social protection: the role of cash transfers. Poverty In Focus.

Irusta, A. (2014). El concepto de Gubernamentalidad, la economización de la política y el problema del estado en Michel Foucault. Philosophia, 74(2), 39-59.

Jäger, S. (2003). Discurso y conocimiento: aspectos teóricos y metodológicos de la crítica del discurso y del análisis de dispositivos. En R. Wodak \& M. Meyer (Eds.), Métodos de análisis crítico del discurso. Barcelona: Gedisa.

Martin, M. P. (2016). Cambio o continuidad de las políticas de protección social en Chile en gobiernos de centroizquierda y centroderecha. Reforma y Democracia, (64), 193-224.

Martínez, R., \& Soto, E. (2012). El Consenso de Washington: la instauración de las políticas neoliberales en América Latina. Política y Cultura, (37), 35-64.

Meyer, M. (2003). Entre la teoría, el método y la política: la ubicación de los enfoques relaciondos con al ACD. En R. Wodak \& M. Meyer (Eds.), Métodos de análisis crítico del discurso. Barcelona: Gedisa.

Ministerio de Desarrollo Social. (2017). Ingreso Ético Familiar. Recuperado a partir de http://www.ingresoetico.gob.cl/ 
Inti Fernando Fuica Rebolledo, Representaciones del Ingreso Ético Familiar: expresiones de la Gubernamentalidad chilena, perifèria 22(2), diciembre 2017

\section{revistes.uab.cat/periferia}

Monckeberg, M. O. (2011). Los magnates de la prensa: Concentración de los medios de comunicación en Chile. Santiago de Chile: Penguin Random House.

OECD. (2015). Todos juntos ¿Por qué reducir la desigualdad nos beneficia? ... en Chile.

Ruiz Olabuénaga, J. I. (2007). Metodología de la Investigación Cualitativa. Bilbao: Universidad de Deusto.

Segovia, C., \& Gamboa, R. (2015). Imágenes de desigualdad en Chile: El impacto de factores económicos y políticos. Papel Político, 20(2), 1-20. https://doi.org/10.11144/Javeriana.papo20-2.idci

Shore, C. (2010). La Antropología y el estudio de la política pública: reflexiones sobre la "formulación" de las políticas. Antipoda, Revista de Antropología y Arquelogía, (10), 21-49. https://doi.org/10.7440/antipoda10.2010.02

Van Dijk, T. A. (2003). La multidisciplinareidad del análisis crítico del discurso: un alegato a favor de la diversidad. En R. Wodak \& M. Meyer (Eds.), Métodos de análisis crítico del discurso. Barcelona: Gedisa.

Vargas, L. H., \& Socías, F. (2016). El subsistema Seguridades y Oportunidades del Ingreso Ético Familiar de Chile desde un enfoque de derechos:análisis de su trayectoria y de sus desafíos futuros. Revista Opera, 18, 183-202. https://doi.org/10.18601/16578651.n18.10

Wacquant, L. (2010). Castigar a los pobres. El gobierno neoliberal de la inseguridad social. Barcelona: Editorial Gedisa.

Wodak, R. (2003). De qué trata el análisis crítico del discurso (ACD). Resumen de su historia, sus conceptos fundamentales y sus desarrollos. En R. Wodak \& M. Meyer (Eds.), Métodos de análisis crítico del discurso (p. 286). Barcelona: Gedisa. 